\title{
A atuação do Ministério Público na defesa do direito à educação de crianças e adolescentes
}

The role of the Public Ministry in defending the right to education of children and adolescents La actuación del Ministerio Público en la defensa del derecho a la educación de la niñez y la adolescencia

Weslley Alves de Araújo

ORCID: https://orcid.org/0000-0001-6019-6867 Faculdades Integradas do Ceará, Brasil

E-mail: weslley.igt@hotmail.com

Michael Douglas Sousa Leite

ORCID: https://orcid.org/0000-0002-9356-1872

Faculdade Católica Santa Teresinha, Brasil

E-mail: michaeldouglas adm@hotmail.com

Daniel Moura Gouveia

ORCID: https://orcid.org/0000-0002-7551-4271

Universidade Federal de Campina Grande, Brasil E-mail: danielmouragouveia@gmail.com

Agilio Tomaz Marques

ORCID: https://orcid.org/0000-0001-8364-5063

Universidade Federal de Campina Grande, Brasil

E-mail: agiliotomaz@hotmail.com

Kaio Luís de Azevêdo Santos

ORCID: https://orcid.org/0000-0002-5904-8549

Faculdade Católica Santa Teresinha, Brasil E-mail: kaioluis@hotmail.com

Helmo Robério Ferreira de Meneses ORCID: https://orcid.org/0000-0001-9326-8548

Faculdades Integradas do Ceará, Brasil

E-mail: helmo_rob@hotmail.com

Laerte Ferreira de Morais França

ORCID: https://orcid.org/0000-0002-4147-1920

Universidade Federal de Campina Grande, Brasil

E-mail: laertefmf@yahoo.com.br

Glauber Iure Cardoso de Menezes Silva

ORCID: https://orcid.org/0000-0002-8483-4488

Faculdades Integradas do Ceará, Brasil

E-mail: glauber.adv@bol.com.br

Francimara de Sousa Queiroga

ORCID: https://orcid.org/0000-0002-1031-7904

Universidade Federal de Campina Grande, Brasil

E-mail: francimaraqueiroga@gmail.com

Pablo Sthefano Roque de Souza Bandeira

ORCID: https://orcid.org/0000-0002-8980-5977 Universidade Regional do Cariri, Brasil

E-mail: bandeiraroque@gmail.com

Sauly Martinho Gomes de Sousa

ORCID: https://orcid.org/0000-0001-6181-0363

Faculdades Integradas do Ceará, Brasil

E-mail: administracao@sousa.pb.gov.br

Mariana Ferreira Pessoa

ORCID: https://orcid.org/0000-0002-1563-5469

Universidade do Estado do Rio Grande do Norte, Brasil

E-mail:marianafepessoa@gmail.com

Cristiane Modesto de Brito

ORCID: https://orcid.org/0000-0002-4183-7515

Centro Universitário de João Pessoa Brasil

E-mail: cris.modesto@hotmail.com

Aline Cristina de Araújo Florentino Silva

ORCID: https://orcid.org/0000-0002-0091-6946

Faculdades Integradas do Ceará, Brasil

E-mail: alineflorentino.fasp@gmail.com 
ORCID: https://orcid.org/0000-0002-2512-8241

Universidade Federal de Campina Grande, Brasil E-mail: viniciuscamposf@gmail.com

Jefferson Thiago da Silva Victor

ORCID: https://orcid.org/0000-0002-8867-9032 Faculdades Integradas do Ceará, Brasi E-mail: jeffersonethiane10@gmail.com

Lincon Bezerra de Abrantes

ORCID: https://orcid.org/0000-0002-8362-5334 Universidade Federal de Campina Grande, Brasil E-mail: linconabrantes@hotmail.com

Sandra Maijane Soares de Belchior

ORCID: https://orcid.org/0000-0001-5807-2259 Faculdades Integradas do Ceará, Brasil E-mail: sandrabelchior@hotmail.com

Seane da Nóbrega Mascena Dantas

ORCID: https://orcid.org/0000-0003-0172-0125 Universidade Federal de Campina Grande, Brasil E-mail: seanenobrega@gmail.com

Júlia Marcia Lourenço de Almeida Martins Medeiros

ORCID: https://orcid.org/0000-0001-8554-8136 Universidade Federal de Campina Grande, Brasil E-mail: juliaalmeidamartins@gmail.com

\begin{abstract}
Resumo
A constituição de 1988 coloca que a educação é um direito de todos e dever do Estado e da família, sendo promovida e incentivada com a colaboração da sociedade, visando ao pleno desenvolvimento da pessoa, seu preparo para o exercício da cidadania e sua qualificação para o trabalho. Nesse sentido, o presente artigo pretende analisar de forma concisa as formas de atuação do Ministério Público na promoção do direito à educação de crianças e adolescentes no ordenamento jurídico pátrio. Pra tanto, utilizou-se revisão doutrinária, junto com uma análise bibliográfica qualitativa de artigos, teses e dissertações, além de documentos institucionais. De início, percebe-se que o Parquet é a instituição legitimada para defender interesses coletivos, difusos e individuais indisponíveis e é justamente nesse ponto, que o direito básico à educação de crianças e adolescentes ganha destaque, pelo fato de que sua homogeneidade e a transindividualidade autorizam o órgão ministerial a atuar na defesa de tal direito. Ademais, no decorrer do trabalho, foi analisado as principais características do princípio da proteção integral das crianças e dos adolescentes, sempre à luz da Constituição e da Lei 8.069/90, bem como explicitando sua relevância no sistema jurídico brasileiro. Por derradeiro, destaca-se a legitimidade do Ministério Público em propor medidas tendentes a assegurar o direito à educação para as crianças e adolescentes.
\end{abstract}

Palavras-chave: Crianças e adolescentes; Direito; Educação; Ministério Público.

\begin{abstract}
The 1988 Constitution states that education is a right of all and a duty of the State and the family, being promoted and encouraged with the collaboration of society, aiming at the full development of the person, their preparation for the exercise of citizenship and their qualification for the Work. In this sense, this article intends to concisely analyze the forms of action of the Public Ministry in promoting the right to education of children and adolescents in the national legal system. Therefore, a doctrinal review was used, along with a qualitative bibliographic analysis of articles, theses and dissertations, in addition to institutional documents. At first, it is clear that Parquet is the legitimate institution to defend unavailable collective, diffuse and individual interests and it is precisely at this point that the basic right to education of children and adolescents is highlighted, due to the fact that its homogeneity and trans-individuality authorize the ministerial body to act in defense of such right. Furthermore, throughout the work, the main characteristics of the principle of full protection of children and adolescents were analyzed, always in light of the Constitution and Law 8069/90, as well as explaining its relevance in the Brazilian legal system. Lastly, the legitimacy of the Public Ministry in proposing measures to ensure the right to education for children and adolescents is highlighted.
\end{abstract}

Keywords: Children and adolescents; Right; Education; Public Ministry.

\title{
Resumen
}

La Constitución de 1988 establece que la educación es un derecho de todos y un deber del Estado y de la familia, siendo promovida y alentada con la colaboración de la sociedad, buscando el pleno desarrollo de la persona, su preparación para el ejercicio de la ciudadanía y su calificación. para el Trabajo. En este sentido, este artículo pretende analizar de manera concisa las formas de actuación del Ministerio Público en la promoción del derecho a la educación de la niñez y la adolescencia en el ordenamiento jurídico nacional. Para ello, se utilizó una revisión doctrinal, junto con un análisis bibliográfico cualitativo de artículos, tesis y disertaciones, además de documentos institucionales. En un primer 
momento queda claro que el Parquet es la institución legítima para defender los intereses colectivos, difusos e individuales indisponibles y es precisamente en este punto donde se destaca el derecho básico a la educación de la niñez y la adolescencia, debido a que su homogeneidad y trans. -La individualidad autoriza al organismo ministerial a actuar en defensa de tal derecho. Además, a lo largo del trabajo, se analizaron las principales características del principio de protección integral de la niñez y la adolescencia, siempre a la luz de la Constitución y la Ley 8069/90, además de explicar su relevancia en el ordenamiento jurídico brasileño. Por último, se destaca la legitimidad del Ministerio Público en proponer medidas para garantizar el derecho a la educación de la niñez y la adolescencia.

Palabras clave: Niños y adolescentes; Derecha; Educación; Ministerio Público.

\section{Introdução}

A educação é um direito social, prescrito na Constituição Federal, e, portanto, se encontra em o rol das providências estatais que não estão na margem da discricionariedade dos agentes públicos. Falar em direito à educação é, sobretudo, discorrer sobre o desenvolvimento da pessoa humana, sendo possível presumir, por este prisma, que os demais direitos sociais estão, indiretamente, intrínsecos aos desdobramentos do acesso à educação (Constituição da República Federativa do Brasil de 1988).

A infância e a adolescência, por outro lado, também têm amparo legal, tanto no âmbito da lei fundamental, no mesmo capítulo da Carta Magna, quanto das leis extravagantes. É possível afirmar que, no Brasil, o arcabouço legal oportuniza um ambiente legal que promove proteção à pessoa, desde o seu nascimento. Isso se dá pelas vias de prioridade e pelo leque de garantias, oferecidas pela legislação que foi articulada com fins de garantir o desenvolvimento pleno e equitativo às crianças e adolescentes.

Em linhas gerais, o Estado deve garantir o ensino público a todos, indistintamente. O que significa que no Brasil cada ente federado, dentro de sua competência, deve prover o acesso universal e gratuito à educação de qualidade. Além disso, o Brasil assumiu, perante a Organização das Nações Unidas - ONU, o compromisso lavrado com Objetivos de Desenvolvimento Sustentável (ODS), de colaborar e investir na perseguição dos objetivos e metas globais, no período compreendido entre 2017 a 2030. Dentre os 17 objetivos, está o dever de assegurar a educação inclusiva e equitativa e de qualidade, e promover oportunidades de aprendizagem ao longo da vida para todos (ODS 4) (ONU, 2015).

A infância e a adolescência, por sua vez, são acontecimentos em constante evolução, decorridos por dimensões socioeconômicas, política, geográfica, psicológica, religiosa e familiar. Assim, torna-se relevante debater alguns fatores de risco dessa faixa populacional, visando políticas públicas, sendo necessário compreender os riscos como processos relacionados a diversos fatores (Yunes \& Szymansky, 2001).

Um desses fatores é a pobreza e todas as infinidades de problemas associados a ela, que obstam a vida de uma grande parte de pessoas em todo o mundo. Para se ter uma ideia, segundo dados recentes ONU (2020), 40\% das crianças e dos adolescentes tentam sobreviver em países subdesenvolvidos com menos de um dólar ao dia. Essas crianças e adolescentes não representam apenas uma parcela significativa da população mais pobre do mundo, como ainda são acometidos pela pobreza em um estágio crítico de suas vidas, o que lhes compromete o desenvolvimento e provoca efeitos danosos de longa duração, tanto físicos quanto psicossociais.

A pobreza quase sempre acompanha o desrespeito aos direitos fundamentais, não sendo diferente em relação com as crianças e adolescentes. Segundo ainda a ONU (2020), existe no mundo mais de 300 milhões de crianças fora da escola. O Brasil infelizmente possui um alto número de crianças e adolescentes em situações de risco. Um estudo lançado pelo Fundo das Nações Unidas para a Infância - Unicef aponta que o país tem 1,4 milhão de crianças/adolescentes fora das escolas (ONU, 2020).

Um meio pelo qual essas crianças e adolescentes podem ter oportunidade de sair dessa situação de risco é a educação, que representa um processo contínuo de construção do ser humano e integração de todas as dimensões de nossa vida: saberes, aptidões, habilidades, capacidade de discernimento e ação (Florentino, 2014). Nesse aspecto, a educação contribui para o aperfeiçoamento profissional, intelectual e emocional do ser humano (Nunes, 2015). 
Nesse aspecto, é importante destacar que é dever do Ministério Público ser o órgão articulador na busca de garantir ao cidadão, em especial as crianças e adolescentes, o direito a uma educação de qualidade, pois é uma instituição independente, autônoma, e defensora da ordem jurídica, dos interesses sociais, difusos e coletivos, segundo dispõe a Constituição (Moraes, 2014; Masson, 2021).

O Ministério Público é instituição permanente, essencial à função jurisdicional do Estado, incumbindo-lhe a defesa da ordem jurídica, do regime democrático e dos interesses sociais e individuais indisponíveis (Constituição da República Federativa do Brasil de 1988). Percebe-se, pela análise conceitual do Ministério Público e seu papel no Estado brasileiro, que o sistema de justiça dispõe de um órgão com a incumbência de zelar e promover, mediante a atuação custos legis, os direitos fundamentais, sejam eles individuais ou difusos, os sociais e indisponíveis.

Logo, é possível identificar que o Ministério Público atua, mediante o acompanhamento das políticas públicas que possam efetivar o direito à educação, bem como o monitoramento desta garantia legal às crianças e adolescentes, com vistas à observância da prioridade na aplicação dos recursos públicos para fins de investimento em ações governamentais.

As ações do Parquet, com propósito de garantir a implementação dos ditames constitucionais que efetivem o direito à educação, podem ser vislumbradas mediante o recebimento de denúncias nas promotorias de justiça, em cada território, com intuito de investigar irregularidades, a exemplo de falta de vagas em creches e escolas do ensino público, indicadores relevantes como evasão escolar, quantidade de crianças ou adolescentes fora da escola, inadequação da infraestrutura mínima, acessibilidade das crianças e adolescentes portadores de necessidades especiais, etc.

Os órgãos ministeriais têm, cada vez mais, se apoderado do papel de efetivo promotor de direitos sociais e, nesse diapasão, é relevante observar que organizaram sua estrutura para o atendimento especializado de procedimentos que visem garantir o direito à educação e à infância e juventude. Assim, instituíram Promotorias de Educação e da Infância e Juventudes, enquanto instâncias, organizadas internamente, em cada Promotoria de Justiça, bem como Centros de Apoio Operacional às Promotorias de Justiça (CAOP) de Educação e Defesa da Criança e do Adolescente.

Assim, o presente trabalho busca analisar de forma concisa as formas de atuação do Ministério Público na promoção do direito à educação de crianças e adolescentes no ordenamento jurídico pátrio.

\section{Metodologia}

O presente artigo trata-se de um estudo exploratório, com abordagem qualitativa, de cunho bibliográfico. Segundo Poupart et al., (2008) a pesquisa de abordagem qualitativa refere-se a uma área que busca examinar e esclarecer as questões mais complexas que aparecem ao longo da pesquisa, a mesma detalha as particularidades, sua análise de dados é mais aprofundada no que diz respeito às práticas, costumes e a propensão a determinados comportamentos.

A pesquisa de caráter exploratório tem como finalidade identificar melhor ou fazer uma sondagem acerca de um fato ou fenômeno, na maioria das vezes retrata visões e conceitos novos, que tem pouco ou nenhum conhecimento na literatura, dessa forma, a mesma oferece subsídios para os estudos realizados posteriormente sejam produzidos com maior propriedade (Marconi \& Lakatos, 2017).

A pesquisa utilizou uma revisão doutrinária, junto com uma análise bibliográfica qualitativa de artigos, teses e dissertações, além de documentos institucionais.

\section{A Proteção Integral à Criança e ao Adolescente Imposta pela Constituição Federal}

Primeiramente, mencione-se que a Lei n. ${ }^{\circ}$ 8.069/90, conhecida como Estatuto da Criança e do Adolescente - ECA regimentou a doutrina da Proteção Integral, adotada pelo ordenamento jurídico na Constituição Federal de 1988 (Liberati, 2006). 
De acordo com essa doutrina, as crianças/adolescentes são destinatários de todos os direitos fundamentais conferidos à pessoa adulta, e, ainda, de outros, especiais, em fundamento de sua condição de seres em desenvolvimento (Muller, 2011; Barros, 2017).

Neste sentido, dispõe o Estatuto da Criança e do Adolescente, em seu art. $3^{\circ}$, que a criança ou adolescente gozam de todos os direitos básicos característicos à pessoa humana, sem nulo prejuízo da proteção integral de que trata esta Lei, assegurados por lei ou por outros instrumentos, todas as oportunidades/facilidades, com a razão de facultar o desenvolvimento social, físico, moral, mental e espiritual em condições de liberdade/dignidade (Lei n. ${ }^{\text {o }} 8.069$ de 13 de julho de 1990).

Para assegurar a crianças e adolescentes o desenvolvimento sadio e harmônico, previsto no dispositivo supra, estabeleceu a referida lei no seu art. $4^{\circ}$ que é encargo/dever da família, comunidade ou sociedade em geral e Poder Público assegurar, com máxima prioridade, a efetivação de direitos referentes à vida, alimentação, cultura, saúde, educação, esporte e lazer, profissionalização, respeito, liberdade, dignidade e convivência familiar/comunitária (Lei n. ${ }^{\circ} 8.069$ de 13 de julho de 1990 ).

A citada lei prescreve ainda, em seu art. 70, o dever de todos prevenir a ocorrência de ameaça ou violação dos referidos direitos (Lei n. ${ }^{\circ} 8.069$ de 13 de julho de 1990). De acordo com o estabelecido no parágrafo único do mencionado art. $4^{\circ}$ do ECA, a garantia da absoluta prioridade importa em assegurar as crianças e aos adolescentes: a) a primazia em receber socorro e proteção em qualquer situação; b) a precedência de atendimento em serviços públicos ou relevância pública; c) a preferência na elaboração/formulação e execução das políticas públicas sociais; e d) a destinação de forma privilegiada dos recursos públicos nas áreas conexas com a proteção à infância e juventude (Lei n. 8.069 de 13 de julho de 1990).

Nessa linha de ideias, portanto, cabe ao Poder Público zelar por todos os direitos inerentes à criança e ao adolescente estabelecidos nos artigos $3^{\circ}$ e $4^{\circ}$ da Lei n ${ }^{\circ} 8.069$, de 1990, e, em especial, ao direito à educação, conforme disposto no art. 53º do mesmo diploma legal (Lei n. 8.069 de 13 de julho de 1990; Santos, 2019).

Neste sentido, Barroso e Barcellos (2001) dissertam que o princípio do melhor interesse das crianças e adolescentes tem os seus embriões na Declaração Universal dos Direitos da Criança, acolhida pela Organização das Nações Unidas - ONU, ainda em 1959. Destaca-se ainda a Convenção Americana sobre Direitos Humanos denominada Pacto de San José da Costa Rica, 1969, ratificada em 1992 pelo Brasil (Decreto n. 678 de 1992), que faz menção ao dever da família, sociedade e Estado de dar proteção especial às crianças e aos adolescentes, e a Convenção Internacional de Direitos da Criança, aprovada em 1989 pela ONU e ratificada pelo Decreto 99710 de 1990 no Brasil, dispõe que as ações relativas a crianças levadas a efeito por instituições públicas/privadas deverão considerar, primordialmente, o melhor interesse da criança (Bahia, 2017).

Prosseguindo nessa linha de raciocínio, Barroso e Barcellos (2001) e Bahia (2017) concluem que o antigo Código de Menores já veiculava a ideia do melhor interesse por meio da cognominada "regra de ouro" do Direito Menorista (art. $5^{\circ}$ ), onde o superior interesse do menor, sobrelevaria a qualquer interesse ou bem juridicamente tutelado. De toda sorte, a Constituição de 1988 ofereceu parâmetros: o melhor interesse do menor consistirá na solução que mais realize eficientemente os seus direitos fundamentais, nos quais estão incluídos a educação, a cultura, a profissionalização e a convivência familiar (Barroso \& Barcellos, 2001).

Com base nesse aspecto, evidencia-se o direito subjetivo acima exposto, vinculado intrinsecamente à própria cidadania, em sentido amplo, e à dignidade da criança e do adolescente, que não podem ser negadas (Campos, 2009).

Nesse ponto, saliente-se que o ECA estabelece que o não oferecimento do ensino obrigatório pelo Poder Público ou sua oferta irregular importa responsabilidade da autoridade competente, conforme art. $53^{\circ}, \S 2^{\circ}$ do seu texto. Outrossim, o art. $208^{\circ}$, parágrafo $2^{\circ}$ da Constituição Federal dispõe exatamente no mesmo sentido (Constituição da República Federativa do Brasil de 1988; Lei n. ${ }^{\circ} 8.069$ de 13 de julho de 1990).

E não se pode negar que os professores, além das demais autoridades vinculadas à educação, são protagonistas do processo educacional dos alunos e são também responsáveis pela regular oferta de ensino (Barroso, 2017). 
Neste diapasão, faz-se necessário transcrever lição de Barroso (2017), que trata acerca do princípio constitucional da efetividade, onde a ideia de efetividade, traduz nos últimos tempos a mais notável preocupação do constitucionalismo, conexa ao fenômeno da juridicização da Constituição, e ao incremento e reconhecimento de sua força normativa, a efetividade merece um capítulo obrigatório na interpretação constitucional. Os grandes autores da atualidade se referem à necessidade de dar preferência, nos programas constitucionais, aos pontos de vista que levem as normas a obterem a eficácia máxima ante as circunstâncias de cada caso (Barroso, 2017).

Segundo ainda Barroso (2017), as ideias até aqui desenvolvidas em nome do princípio da efetividade mostram para uma evidência: o direito existe para se realizar. O direito constitucional não foge a esse desígnio. Como orienta Biscaretti Di Ruffia (1984), sendo a Constituição a própria ordenação suprema do Estado, não pode existir uma norma ulterior, de grau superior, que a proteja; como consequência ela deve encontrar em si mesma própria tutela e garantia. Convém, neste passo, enfatizar, ainda uma vez, a ideia da força normativa da Constituição.

Com base no entendimento acima exposto, percebe-se que o movimento da máxima efetividade pressupõe um compromisso do jurista com o incremento da força normativa da Constituição. Não se trata mais de, passivamente, fazer opções entre textos diferentes, que deverão, um ou outro, se aplicar a um caso real/concreto, contudo de mobilizar formas processuais, argumentos, doutrinas - enfim, os instrumentos que a dogmática proporciona - para a plena aplicação do Texto Maior. O elemento gramatical perde um pouco da importância que a hermenêutica tradicional lhe atribuía.

Em suma, a tese da máxima efetividade é um desdobramento do reconhecimento da força normativa da Constituição. Partindo do pressuposto de que tudo na Constituição é norma, e norma suprema, seus cultores passaram a enfatizar uma atuação que tivesse em vista não apenas a eficácia jurídica, mas principalmente a efetividade, a formulação de estratégias jurídicas para a transformação do dever ser em realidade.

Dessa forma, portanto, os interesses de crianças e adolescentes são prioritários e devem prevalecer diante de situações que causem ou possam vir a causar prejuízos ao direito à educação desses hipossuficientes matriculados nas instituições de ensino brasileiras.

\section{Competência para Legislar em Matéria Educacional}

$\mathrm{Na}$ leitura dos dispositivos constitucionais relativos à educação, nota-se claramente a determinação do legislador constituinte, que estabeleceu de um regime de colaboração entre os diversos entes federados.

Nessa esteira, a Carta Magna de 1988, em seu art. 205 , define responsabilidade comum às pessoas jurídicas de direito público interno, o que é respaldado pelo art. $208^{\circ}$ (Constituição da República Federativa do Brasil de 1988).

No art. $211^{\circ}$ e seus parágrafos, a Lei Maior, como norma de princípio programático endereçada ao Poder Público, estabelece as competências materiais de cada esfera governamental, onde a União, Estados, o Distrito Federal e Municípios deverão organizar em regime de colaboração os seus sistemas de ensino:

$\S 1^{\text {o }}$ A União organizará o sistema federal de ensino e o dos Territórios, financiará as instituições de ensino públicas federais e exercerá, em matéria educacional, função redistributiva e supletiva, de forma a garantir equalização de oportunidades educacionais e padrão mínimo de qualidade do ensino mediante assistência técnica e financeira aos Estados, ao Distrito Federal e aos Municípios:

$\S 2^{\circ}$ Os Municípios atuarão prioritariamente no ensino fundamental e na educação infantil.

$\S 3^{\circ}$ Os Estados e o Distrito Federal atuarão prioritariamente no ensino fundamental e médio.

$\S 4^{\circ} \mathrm{Na}$ organização de seus sistemas de ensino, a União, os Estados, o Distrito Federal e os Municípios definirão formas de colaboração, de modo a assegurar a universalização do ensino obrigatório.

$\S 5^{\circ}$ A educação básica pública atenderá prioritariamente ao ensino regular (Constituição da República Federativa do Brasil de 1988). 
Ademais, por sua vez, a Lei de Diretrizes e Bases da Educação - LDB (Lei 9.394/96), ao regulamentar o dispositivo constitucional, embora tenha acrescido a função normativa ao ente federal, previu expressamente a liberdade de organização dos sistemas de ensino, consoante se depreende do artigo $8^{\circ}$ e seus parágrafos, in verbis:

Art. $8^{\circ}$ A União, os Estados, o Distrito Federal e os Municípios organizarão, em regime de colaboração, os respectivos sistemas de ensino.

$\S 1^{\circ}$ Caberá à União a coordenação da política nacional de educação, articulando os diferentes níveis e sistemas e exercendo função normativa, redistributiva e supletiva em relação às demais instâncias educacionais.

$\S 2^{\circ}$ Os sistemas de ensino terão liberdade de organização nos termos desta Lei (Lei n. ${ }^{\circ} 9.394$ de 20 de dezembro de 1996).

Interpretando o artigo citado, conclui-se que, embora a União possa exercer plenamente a sua função normativa, através de seus órgãos, com destaque para o Conselho Nacional de Educação, deverá obrigatoriamente respeitar a liberdade de organização dos sistemas de ensino, sob pena de ilegalidade.

Por outro lado, além da função supletiva e residual em suas responsabilidades para com a educação, a Lei 9.394/96, em seu art. $9^{\circ}$, trouxe também algumas hipóteses de competência expressa da União, dentre as quais se destaca o que cabe à União: elaborar o Plano Nacional de Educação, em colaboração com Estados, Distrito Federal e Municípios; e estabelecer, em colaboração com Estados, Distrito Federal e Municípios, competências e diretrizes para a educação infantil, ensino fundamental e ensino médio, que nortearão os currículos e os seus conteúdos mínimos, de forma a assegurar uma formação básica comum (Lei n. ${ }^{\circ} 9.394$ de 20 de dezembro de 1996).

Nesse plano de competência expressa, destaca-se, ainda, a competência legislativa concorrente da União, prevista no art. 24으, inciso IX, da Constituição Federal de 1988, que compete à União, aos Estados e ao Distrito Federal legislar concorrentemente sobre: educação, cultura, ensino e desporto (Constituição da República Federativa do Brasil de 1988). No âmbito da legislação concorrente, a competência da União limitar-se-á a estabelecer normas gerais, onde a competência da União para legislar sobre normas gerais não exclui a competência suplementar dos Estados e inexistindo lei federal sobre normas gerais, os Estados exercerão competência legislativa plena, para suprir a suas peculiaridades (Constituição da República Federativa do Brasil de 1988).

Ou seja, no que toca à legislação concorrente, a atribuição da União é limitada ao estabelecimento de normas gerais, o que não exclui a competência suplementar dos Estados membros, de maneira que, se não existir lei federal sobre tais normas, os Estados poderão, inclusive, exercer a competência legislativa plena, a fim de atender às suas peculiaridades, conforme estabelece o supracitado artigo (Nunes, 2014).

Da mesma forma, os Municípios podem legislar sobre assuntos de interesse local (art. 30º inciso I, CF/88), baixando "normas complementares para o seu sistema de ensino" (art. 11 ${ }^{\circ}$, inciso III, da Lei n ${ }^{\circ}$ 9.394/96) (Lei n. ${ }^{\circ} 9.394$ de 20 de dezembro de 1996).

Há que se ressaltar, ainda, que o simples fato de constar no art. $22^{\circ}$, inciso XXIV, da CF/88, a competência da União para legislar sobre diretrizes e bases educacionais não exclui a atribuição estadual para normalizar, de modo suplementar, a matéria, nos termos do parágrafo $2^{\circ}$, do art. $24^{\circ}$, da $\mathrm{CF} / 88$, pois ao ente central cabe editar normas gerais (art. $24^{\circ}$, parágrafo $1^{\circ}$ ), enquanto entidades estaduais, em caráter suplementar, podem legislar normas específicas, para atenderem suas peculiaridades (Constituição da República Federativa do Brasil de 1988; Moraes, 2014).

De forma mais explicativa, Silva (2014) leciona no seguinte sentido, que a legislação concorrente da União sobre as matérias indicadas supra se limitará a estabelecer normas gerais. Nisso, a Constituição de 1988 foi, algumas vezes, redundante, por exemplo, no art. $22^{\circ}$, XXIV, relata como privativo da União legislar acerca das diretrizes e bases da educação nacional, enquanto, no artigo $24^{\circ}$, IX, declara caber-lhe legislar sobre normas gerais de educação, contudo não há nada de incoerência 
nisso, como pode parecer, pois legislar sobre diretrizes e bases da educação nacional e normas gerais de educação no fundo explicitam a mesma finalidade normativa (Constituição da República Federativa do Brasil de 1988).

A tradição fez com que os educadores da Constituinte mantivessem a regra de 1946, que dava à União competência para legislar sobre as diretrizes e bases da educação nacional, mas não poderiam também deixar de incluir na competência comum legislar acerca da educação, situação em que a União só tem jurisdição para fixar normas gerais (Silva, 2014). Nos termos do parágrafo $2^{\circ}$ do art. $24^{\circ}$, a competência da União para legislar sobre normas gerais não exclui (na realidade até pressupõe) a competência suplementar dos Estados, e isso abrange não somente as normas gerais referidas no parágrafo $1^{\circ}$ do art. $24^{\circ}$, contudo as normas gerais indicadas também em outros dispositivos constitucionais, porque justamente a característica da legislação principiológica (normas gerais, diretrizes, bases), na repartição de competências federativas, consiste na sua correlação com competência suplementar (complementar e supletiva) dos Estados (Constituição da República Federativa do Brasil de 1988).

Observa-se, pois, que, tanto os dispositivos constitucionais, quanto a legislação ordinária, são uníssonos ao estabelecer uma política de colaboração entre os diversos entes federados, de modo que à União caberá a coordenação da política nacional da educação, com o estabelecimento de regras e diretrizes gerais para a educação básica, sem, contudo, excluir a liberdade dos demais entes federativos de legislarem e organizarem seus sistemas de ensino (Barroso, 2017).

Dessa forma, Estados e Municípios podem perfeitamente se organizar e gerir os seus sistemas de ensino, na qualidade de entidades autônomas, para atenderem às suas peculiaridades regionais e locais.

\section{A Legitimidade do Ministério Público em Defender e Promover o Direito à Educação}

$\mathrm{O}$ direito à educação, consagrado no art. $6^{\circ}$ da Carta Magna, está disciplinado pormenorizadamente nos artigos $205^{\circ} \mathrm{a}$ $214^{\circ}$ da Constituição (Constituição da República Federativa do Brasil de 1988). Os dispositivos então mencionados já foram densificados pelo legislador ordinário, através, sobretudo, do Estatuto da Criança e do Adolescente e da Lei de Diretrizes e Bases da Educação.

Destaca-se o parágrafo primeiro do art. $208^{\circ}$, que expressamente qualifica como direito público subjetivo o acesso ao ensino fundamental, obrigatório e gratuito, dispondo o seu parágrafo segundo que o não oferecimento do ensino obrigatório pelo Poder Público ou sua oferta irregular importa responsabilidade da autoridade competente e dever do Estado com a educação sendo efetivado mediante a garantia de, primeiro, o acesso ao ensino obrigatório e gratuito é direito público subjetivo e, segundo, o não-oferecimento do ensino obrigatório pelo Poder Público, ou sua oferta irregular, importam responsabilidade da autoridade competente (Constituição da República Federativa do Brasil de 1988).

Como se vê, o acesso ao ensino obrigatório, tal como assegurado na Constituição, se constitui em direito público subjetivo, o que confere a cada pessoa o direito de exigi-lo do Poder Público. Ademais, o art. 212 ${ }^{\circ}$, do Estatuto da Criança e do Adolescente, expressamente admite "todas as espécies de ações pertinentes" para a consecução dos objetivos previstos em seu texto (Lei n. ${ }^{\circ} 8.069$ de 13 de julho de 1990).

Sobre o tema em comento, destaca-se excerto extraído de julgamento do Recurso Especial no 577.573, de relatoria do Ministro João Otávio de Noronha, verbis:

Consagrado por um lado o dever do Estado, se revela, pelo outro ângulo, o direito subjetivo da criança. Consectariamente, em função do princípio da inafastabilidade da jurisdição consagrado constitucionalmente, a todo direito corresponde uma ação que o assegura, sendo certo que todas as crianças nas condições estipuladas pela lei encartam se na esfera desse direito e podem exigi-lo em juízo (Superior Tribunal de Justiça, Segunda Turma, Recurso Especial no 577573, Rel. Min. João Otávio de Noronha, DJE 06/11/2008). 
Desta forma, haja vista tratarem-se de direitos públicos subjetivos, todas as medidas processuais admitidas em nossa ordem jurídica, ou que de qualquer outro modo levem à implementação destes direitos, poderão e deverão ser tomadas.

Nesse ponto, faz-se necessário dissertar, ainda que de forma concisa, sobre a legitimidade do Ministério Público na defesa de direitos coletivos, difusos e individuais indisponíveis.

A Carta Magna de 1988, ao definir o Ministério Público como instituição permanente, essencial à função jurisdicional do Estado, incumbiu-lhe a defesa da ordem jurídica, do regime democrático e dos interesses sociais e individuais indisponíveis, conforme art. $127^{\circ}$ da Lei Maior (Constituição da República Federativa do Brasil de 1988).

Ademais, em seu art. $129^{\circ}$, estabeleceu suas funções institucionais, destacando-se as funções institucionais do Ministério Público, que é promover o inquérito civil e ação civil pública, para proteção do patrimônio público/social, do meio ambiente e de outros interesses difusos e coletivos (Constituição da República Federativa do Brasil de 1988).

Mais à frente, a Constituição em seu art. $205^{\circ}$, estabelece que a educação é um direito de todos e dever do Estado e família, sendo incentivada e promovida com a colaboração da sociedade, olhando ao pleno desenvolvimento da pessoa, o seu preparo para o exercício da cidadania e a sua qualificação para o trabalho (Constituição da República Federativa do Brasil de 1988).

A Lei 8.069/90, por sua vez, ao disciplinar as funções do Ministério Público, no que tange aos direitos das crianças e dos adolescentes, dispôs em seu art. $201^{\circ}$, competir ao Ministério Público, entre outras atribuições a de promover o inquérito civil e ação civil pública para a proteção dos interesses individuais, difusos ou coletivos relativos a infância e a adolescência e zelar pelo efetivo respeito aos direitos e garantias legais assegurados às crianças e adolescentes, promovendo as medidas judiciais e extrajudiciais cabíveis (Lei n. ${ }^{\circ} 8.069$ de 13 de julho de 1990).

Dispôs ainda no art. $210^{\circ}$, inciso I, que para as ações cíveis fundadas em interesses coletivos e difusos, se consideram legitimados concorrentemente o Ministério Público. No mesmo aspecto, a Lei Complementar de n. 75 de 1993 (Lei Orgânica do Ministério Público da União) dispõe acerca da possibilidade de o Ministério Público ajuizar ação civil pública para a proteção dos direitos constitucionais e interesses individuais indisponíveis, difusos/coletivos relativos à criança e ao adolescente, in verbis:

Art. $6^{\circ}$, compete ao Ministério Público da União:

VII - promover o inquérito civil e ação civil pública para:

a) a proteção dos direitos constitucionais;

c) a proteção dos interesses individuais indisponíveis, difusos e coletivos, relativos às comunidades indígenas, à família,

à criança, ao adolescente, ao idoso, às minorias étnicas e ao consumidor;

d) outros interesses individuais indisponíveis, homogêneos, sociais, difusos e coletivos (Lei Complementar $\mathrm{n} .^{\circ}$ 75, de

20 de maio de 1993).

O art. 5º da referida Lei (n. 75 de 1993) prevê, ainda, que são funções institucionais do Ministério Público da União: a defesa dos seguintes bens e interesses, os direitos e interesses coletivos, especialmente das comunidades indígenas, da família, da criança, do adolescente e do idoso (Lei Complementar n. ${ }^{\circ}$ 75, de 20 de maio de 1993).

Determinações análogas se encontram presentes na Lei n 8.625/93, que instituiu a Lei Orgânica Nacional do Ministério Público, preconizando, no art. $25^{\circ}$, que, além das funções que são previstas nas Constituições Estadual e Federal, na Lei Orgânica e em também outras leis, ainda incumbe ao Ministério Público: Promover o inquérito civil e a ação civil pública, na forma da lei, para a proteção, reparação e prevenção dos danos causados ao consumidor, meio ambiente, direitos e bens de valor artístico, histórico, estético, paisagístico e turístico, e a outros interesses difusos, individuais e coletivos indisponíveis e homogêneos (Lei n. ${ }^{\circ} 8.625$ de 12 de fevereiro de 1993). 
Não é necessário ressaltar o caráter de indisponibilidade de que os direitos referentes à proteção à criança e ao adolescente se revestem, notadamente o direito à educação. Decorre, daí, a inegável legitimação do Ministério Público para sua defesa, haja vista a natureza de tais direitos, que devem ser protegidos com a mais absoluta prioridade.

E, para tanto, a Lei n..$^{\circ}$ 7.347/85, assim como as posteriores, e a própria Constituição, ao tratarem da Ação Civil Pública, não a restringiram à iniciativa do Ministério Público, mas a prática tem demonstrado que é este, em regra, que tem ajuizado as ações de que cuida o Estatuto da Criança e do Adolescente (Lei n. 7.347 de 24 de julho de 1985).

Nesse ponto, importante citar o que prescreve o artigo $1^{\circ}$ da Lei da Ação Civil Pública, verbis: regem-se pelas disposições desta Lei, sem prejuízo da ação popular, as ações de responsabilidade por danos morais e patrimoniais causados: a qualquer outro interesse difuso ou coletivo (Lei n. 7.347 de 24 de julho de 1985).

Quanto à defesa, por parte do Ministério Público, dos interesses difusos e coletivos, em geral, aplica-se perfeitamente o artigo acima citado, que tem aplicação nos casos em que são protegidos interesses difusos e coletivos, juntamente com o Estatuto da Criança e do Adolescente, tendo em vista a natureza dos direitos tutelados.

Nesse ponto, disserta com maestria Mazzilli (2014) no sentido de que confere a Lei n. 8.069 de 1990 iniciativa ao Ministério Público para a ação civil pública, na área da infância e da juventude, até mesmo no tocante à defesa de interesses individuais, dado seu caráter de indisponibilidade. Assim, o Ministério Público poderá ingressar com ação civil pública para assegurar vaga em escola tanto para uma única criança, como uma dezena, centenas ou milhares delas; tanto para se dar escolarização ou profissionalização a um, como a diversos adolescentes privados de liberdade. Da mesma forma, poderá ajuizar ações civis públicas na defesa quaisquer interesses individuais homogêneos, coletivos ou difusos de crianças ou adolescentes (Lei n. ${ }^{\circ} 8.069$ de 13 de julho de 1990).

O Estatuto da Criança e do Adolescente, por sua vez, também fornece subsídios para a instituição do instituto processual do litisconsórcio entre o Ministério Público Federal e o Ministério Público Estadual, por meio do disposto no art. $210^{\circ}$, parágrafo $1^{\circ}$, do referido diploma legal, que determina: para as ações cíveis fundadas em interesses coletivos ou difusos, consideram-se legitimados concorrentemente: O Ministério Público. Admitir-se-á litisconsórcio facultativo entre os Ministérios Públicos da União e dos Estados na defesa dos interesses e direitos de que cuida esta Lei (Lei n. ${ }^{\circ} 8.069$ de 13 de julho de 1990).

Inegável, em consequência, a possibilidade do litisconsórcio ativo nas matérias acima tratadas, tendo em vista, inclusive, que o Ministério Público é órgão incumbido constitucional e legalmente da defesa dos direitos e interesses das crianças e dos adolescentes.

Ainda no que diz respeito à legitimidade do Ministério Público, faz-se mister observar que a natureza dos direitos que o Parquet visa defender através da propositura de ações civis públicas não pode ser enquadrado na esfera restrita dos direitos individuais homogêneos. Isso ocorre tendo em vista a dimensão e a relevância social que pode assumir a tutela dos direitos afetos às crianças e adolescentes.

Tais direitos, por sua própria natureza, revestem-se de caráter muito mais amplo do que aquele característico de um grupo isolado de pessoas, já que dizem respeito à sociedade como um todo.

Por oportuno, interessante mencionar o entendimento do Ministro Celso de Mello, ex-presidente do Pretório Excelso, no RTJ 147/161, lecionando sobre a ampliação das atribuições do Ministério Público com o advento da Constituição da República de 1988, ipsis verbis:

Com a reconstrução da ordem constitucional, emergiu o MP sob o signo da legitimidade democrática. Ampliaram-se lhe as atribuições; dilatou-se lhe a competência; reformularam-se lhe os meios necessários à consecução de sua destinação constitucional; atendeu-se, finalmente, a antiga reivindicação da própria sociedade civil. Posto que o MP não constitui órgão ancilar do governo, instituiu o legislador constituinte um sistema de garantias destinado a proteger o 
membro da instituição e a própria instituição, cuja autuação autônoma configura a confiança de respeito aos direitos, individuais e coletivos, e a certeza de submissão dos Poderes à lei (Supremo Tribunal Federal, 1992).

Ademais, no tocante ao tema educação, o Ministério Público pode incentivá-lo, conforme julgado abaixo transcrito:

RECURSO EXTRAORDINÁRIO. CONSTITUCIONAL. LEGITIMIDADE DO MINISTÉRIO PÚBLICO PARA PROMOVER AÇÃO CIVIL PÚBLICA EM DEFESA DOS INTERESSES DIFUSOS, COLETIVOS E HOMOGÊNEOS. MENSALIDADES ESCOLARES: CAPACIDADE POSTULATÓRIA DO PARQUET PARA DISCUTI-LAS EM JUÍZO. 1. A Constituição Federal confere relevo ao Ministério Público como instituição permanente, essencial à função jurisdicional do Estado, incumbindo-lhe a defesa da ordem jurídica, do regime democrático e dos interesses sociais e individuais indisponíveis (CF, art. 127). 2. Por isso mesmo detém o Ministério Público capacidade postulatória, não só para a abertura do inquérito civil, da ação penal pública e da ação civil pública para a proteção do patrimônio público e social, do meio ambiente, mas também de outros interesses difusos e coletivos (CF, art. 129, I e III). 3. Interesses difusos são aqueles que abrangem número indeterminado de pessoas unidas pelas mesmas circunstâncias de fato e coletivos aqueles pertencentes a grupos, categorias ou classes de pessoas determináveis, ligadas entre si ou com a parte contrária por uma relação jurídica base. 3.1. A indeterminidade é a característica fundamental dos interesses difusos e a determinidade a daqueles interesses que envolvem os coletivos [...] 5.1 Cuidando-se de tema ligado à educação, amparada constitucionalmente como dever do Estado e obrigação de todos (CF, art. 205), está o Ministério Público investido da capacidade postulatória, patente a legitimidade ad causam, quando o bem que se busca resguardar se insere na órbita dos interesses coletivos, em segmento de extrema delicadeza e de conteúdo social tal que, acima de tudo, recomenda-se o abrigo estatal [...] (Supremo Tribunal Federal, 2001).

Nessa ordem de ideias, tanto pela norma constitucional que ampliou as funções institucionais do Ministério Público, quanto pela legislação complementar, que instituiu as suas competências, se tem legítima a atuação Ministerial na defesa de direitos indisponíveis, difusos e coletivos, e notadamente na promoção do direito à educação das crianças e adolescentes.

\section{Considerações Finais}

Diante de tudo o que foi exposto, não restam dúvidas da legitimidade do Ministério Público em promover ações em defesa do direito à educação, já que além de nítido interesse coletivo e individual homogêneo, há relevante conteúdo social. No caso em tela, destaca-se o direito à educação de crianças e adolescentes, pois envolve diretamente interesses coletivos de hipossuficientes, que de forma reflexa ou secundária atende à defesa de interesses individuais indisponíveis.

E é justamente nesse ponto que ganha relevo a atuação do Parquet, o qual tem plena legitimidade para agir, promovendo e defendendo esse direito, seja de forma judicial ou extrajudicialmente. Nessa senda, é patente a presença de interesse social relevante na promoção do direito à educação dos jovens, posto que muitos deles compõem exatamente a parcela dos menos favorecidos socialmente, que são usuários da rede pública de ensino, e, não raro, sofrem violações em seus direitos, dentre os quais, cite-se a falta de qualidade na educação.

Desta feita, com a análise da legislação, da doutrina e dos julgados transcritos acima, objetiva-se demonstrar como o Ministério Público atua para tutelar o direito básico à educação de que são titulares as crianças e os adolescentes que, embora vítimas de atos arbitrariamente praticados e de normas que afrontam seus direitos básicos, são credores de benefícios assegurados tanto pela Constituição Federal quanto pelo Estatuto da Criança e do Adolescente.

Como sugestões de futuras pesquisas, destaca-se a necessidade de analisar a mobilização por parte do Estado, da sociedade e da família em garantir que os direitos estabelecidos sejam realmente efetivados, estabelecendo um trabalho articulado e multidisciplinar que garanta que essa criança ou adolescente seja atendido em todos os aspectos e meios que os envolvem. 


\section{Referências}

Bahia, C. J. A. (2017). Família. Enciclopédia jurídica da PUC-SP. Celso Fernandes Campilongo, Alvaro de Azevedo Gonzaga e André Luiz Freire (coords.). Tomo: Direito Administrativo e Constitucional. Vidal Serrano Nunes Jr., Maurício Zockun, Carolina Zancaner Zockun, André Luiz Freire (coord. de tomo). Pontifícia Universidade Católica de São Paulo.

Barros, C. R. (2017). Abandono Afetivo e os Limites do Dever de Indenizar. JusBrasil. https://jus.com.br/artigos/57256/abandono-afetivo-e-os-limites-do-deverde-indenizar

Barroso, L. R. (2017). Interpretação e aplicação da constituição. (7a ed.), Saraiva.

Barroso, L. R., \& Barcellos, A. P. de. (2001). Regime jurídico da participação de crianças e adolescentes e programas de televisão. Revista Trimestral de Direito Civil, 2 (7), 23-25.

Campos, M. S. V. de O. (2009). Estatuto da criança e do adolescente: A proteção integral e suas implicações político-educacionais. Dissertação de Mestrado: Faculdade de Ciências e Letras, Campus de Araraquara.

Constituição da República Federativa do Brasil. (1988). Senado.

Di Ruffia, P. B. (1984). Direito Constitucional. Saraiva.

Florentino, B. R. B. (2014). Abuso sexual, crianças e adolescentes: reflexões para o psicólogo que trabalha no CREAS. Fractal, Rev. Psicol. 26(1), 59-70.

Lei n. ${ }^{\circ} 7.347$ de 24 de julho de 1985. (1985). Disciplina a ação civil pública de responsabilidade por danos causados ao meio-ambiente, ao consumidor, a bens e direitos de valor artístico, estético, histórico, turístico e paisagístico e dá outras providências. Brasília: Presidência da República.

Lei n. ${ }^{\circ} 8.069$ de 13 de julho de 1990. (1990). Dispõe sobre o Estatuto da Criança e do Adolescente e dá outras providências. Brasília: Presidência da República.

Lei Complementar n. ${ }^{\circ}$ 75, de 20 de maio de 1993. (1993). Dispõe sobre a organização, as atribuições e o estatuto do Ministério Público da União. Brasília: Presidência da República.

Lei n. ${ }^{\circ} 8.625$ de 12 de fevereiro de 1993. (1993). Institui a Lei Orgânica Nacional do Ministério Público, dispõe sobre normas gerais para a organização do Ministério Público dos Estados e dá outras providências. Brasília: Presidência da República.

Lei n. 9.394 de 20 de dezembro de 1996. (1996). Estabelece as diretrizes e bases da educação nacional. Brasília: Presidência da República.

Liberati, W. D. (2006). Processo Penal Juvenil. Malheiros.

Marconi, M. A, \& Lakatos, E. M. (2017). Técnicas de Pesquisa. Atlas.

Masson, N. (2021). Manual de Direito Constitucional. (9a ed.), JusPodivm.

Mazzilli, H. N. (2014). A defesa dos interesses difusos em juízo: meio ambiente, consumidor, patrimônio cultural, patrimônio público e outros interesses. 27. ed. São Paulo: Saraiva.

Moraes, F. L. (2014). O Direito Fundamental à educação de crianças e adolescentes e os instrumentos jurídicos para redução da infrequência/evasão escolar. Trabalho de Conclusão de Curso: Faculdade de Direito da Pontifícia Universidade Católica do Rio Grande do Sul (PUCRS)

Muller, C. M. (2011). Direitos Fundamentais: a proteção integral de crianças e adolescentes no Brasil. Âmbito Jurídico, 89(1). https://ambitojuridico.com.br/edicoes/revista-89/direitos-fundamentais-a-protecao-integral-de-criancas-e-adolescentes-no-brasil.

Nunes, A. C. O. (2015). O Ministério Público e algumas contribuições possíveis à qualidade da Educação. Caderno Operacional: Ministério Público de São Paulo. http://www.mpsp.mp.br/portal/page/portal/Educacao/qualidade_da_educacao/textos_qualidade_da_educacao.

ONU (2015). Organização das Nações Unidas. Objetivos de Desenvolvimento Sustentável. 2018. https://nacoesunidas.org/pos2015/.

ONU. (2020). Impactos Primários e Secundários da Covid-19 em Crianças e Adolescentes. UNICEF, 21 de outubro de 2020. https://www.unicef.org/brazil/relatorios/impactos-primarios-e-secundarios-da-covid-19-em-criancas-e-adolescentes.

Poupart, J. Deslauriers, J., Groulx, L., Laperriêre, A., Mayer, R., \& Pires, A. (2008). A pesquisa qualitativa: enfoques epistemológicos e metodológicos. Petrópolis, RJ: Vozes.

Santos, Y. M. (2019). Colisão dos direitos fundamentais nas relações familiares. Anais do EVINCI - UniBrasil, Curitiba, 5(1), $229-229$.

Silva, J. A. da. (2014). Curso de direito constitucional positivo. (37a ed.), Malheiros Editores.

Superior Tribunal de Justiça. (2008). Segunda Turma. Recurso Especial n. ${ }^{\circ}$ 577.573. Relator Ministro João Otávio de Noronha.

Supremo Tribunal Federal. (1992). Revista Trimestral de Jurisprudência . $^{o}$ 147/161. Relator Ministro Celso de Melo.

Supremo Tribunal Federal. (2001). Recurso Extraordinário n. $^{\circ}$ 163.231. Relator Ministro Maurício Côrrea.

Yunes, M. A. M., \& Szymanski, H. (2001). Resiliência: noção, conceitos afins e considerações críticas. In: Tavares, J. (Org.). Resiliência e educação. (2a ed.), Cortez. 